\title{
Multigene Genetic Programming for Estimation of Elastic Modulus of Concrete
}

\author{
Alireza Mohammadi Bayazidi, ${ }^{1}$ Gai-Ge Wang, ${ }^{2}$ Hamed Bolandi, ${ }^{3}$ \\ Amir H. Alavi, ${ }^{4}$ and Amir H. Gandomi ${ }^{5}$ \\ ${ }^{1}$ Department of Civil Engineering, Islamic Azad University, Kashmar Branch, Kashmar, Iran \\ ${ }^{2}$ School of Computer Science and Technology, Jiangsu Normal University, Xuzhou, Jiangsu 221116, China \\ ${ }^{3}$ Department of Civil Engineering, Islamic Azad University, Bandar Abbas Branch, Bandar Abbas, Iran \\ ${ }^{4}$ Department of Civil and Environmental Engineering, Michigan State University, East Lansing, MI 48824, USA \\ ${ }^{5}$ Department of Civil Engineering, The University of Akron, Akron, OH 44325, USA
}

Correspondence should be addressed to Amir H. Alavi; alavi@msu.edu

Received 25 January 2014; Accepted 4 April 2014; Published 29 April 2014

Academic Editor: Siamak Talatahari

Copyright (c) 2014 Alireza Mohammadi Bayazidi et al. This is an open access article distributed under the Creative Commons Attribution License, which permits unrestricted use, distribution, and reproduction in any medium, provided the original work is properly cited.

\begin{abstract}
This paper presents a new multigene genetic programming (MGGP) approach for estimation of elastic modulus of concrete. The MGGP technique models the elastic modulus behavior by integrating the capabilities of standard genetic programming and classical regression. The main aim is to derive precise relationships between the tangent elastic moduli of normal and high strength concrete and the corresponding compressive strength values. Another important contribution of this study is to develop a generalized prediction model for the elastic moduli of both normal and high strength concrete. Numerous concrete compressive strength test results are obtained from the literature to develop the models. A comprehensive comparative study is conducted to verify the performance of the models. The proposed models perform superior to the existing traditional models, as well as those derived using other powerful soft computing tools.
\end{abstract}

\section{Introduction}

The importance of elastic modulus of concrete in structural and material engineering is well understood. This parameter has been widely used for the analysis of structure deformations, concrete creep, shrinkage, crack control, and so forth [1-3]. The elastic modulus of concrete can easily be obtained from the slope of a tensile test stress-strain curve. In practical cases, the elastic modulus is mostly calculated using empirical equations proposed by various codes of practice, rather than performing time-consuming laboratory tests. The existing empirical equations are commonly derived via traditional statistical analyses such as regression, which have major drawbacks [3-5]. For instance, the regression modeling is based on predefining the structure of the model with a limited number of linear or nonlinear equations. To cope with such limitations, several alternative soft computing approaches have emerged. One of the main features of the soft computing techniques is that they learn from experience and extract the knowledge contained in the experimental data $[4,5]$. Artificial neural networks (ANNs), fuzzy logic (FL), adaptive neurofuzzy inference system (ANFIS), and support vector machine (SVM) are the well-known soft computing methods. These techniques have been utilized for the prediction of the elastic modulus of normal and high strength concrete [6-10]. The major disadvantage of the ANNs, FL, ANFIS, and SVM is that they are not capable of providing practical prediction equations. To overcome the limitations of such techniques, a new approach, called genetic programming (GP), is proposed by Koza [11]. GP generates simplified prediction equations without assuming prior form of the existing relationship $[5,12-15]$. GP and its variants such as linear genetic programming (LGP), gene expression programming (GEP), and multiexpression programming (MEP) have been successfully applied to the behavioral modeling of elastic modulus of concrete $[3,16,17]$. 


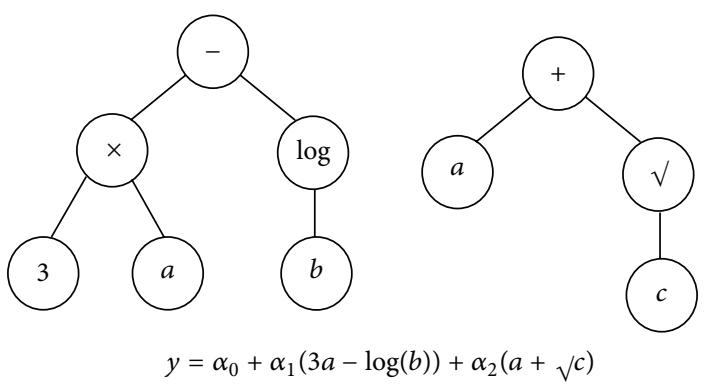

FIGURE 1: A typical program evolved by MGGP.

This study proposes a new multigene genetic programming (MGGP) approach to derive prediction models for the elastic modulus of concrete. MGGP combines the modeling capabilities of both GP and statistical regression methods. Despite remarkable prediction capabilities of the MGGP approach [18], there have been very limited studies focusing on the application of MGGP to civil engineering tasks [19-24]. However, three MGGP-based models are obtained relating the tangent elastic modulus and compressive strength of concrete. A comparative study is conducted between the results obtained by MGGP and those obtained from the buildings codes (i.e., ACI-318-95 [25], NBS [26], CEB-FIB [27], BS-8110 [28], CSA-A23.3 [29], NS-3473 [30], and TS-500 [31]), compatibility aided (i.e., Wee et al. [32] and Gardner and Zhao [33]), FL [6], ANN [7], LGP [3], GEP [16], and MEP [17] models.

\section{Multigene Genetic Programming}

GP creates computer programs to solve a problem by simulating the biological evolution of living organisms [11]. The genetic operators of genetic algorithm (GA) and GP are almost the same. The difference between GA and GP is that the former gives the solution as a string of numbers, while the solution generated by the latter is computer programs represented as tree structures $[3,5,11]$. A comprehensive description of GP can be found in Alavi and Gandomi [5] and Koza [11]. MGGP $[18,34]$ is a new variant of GP. As discussed, the traditional GP representation is based on the evaluation of a single tree (model) expression. In MGGP, a single GP individual (program) is derived from a number of genes, each of which is a tree expression $[18,19]$. In other words, each model evolved by MGGP is a weighted linear combination of the outputs from a number of GP trees. The tress are called "gene." Figure 1 shows a typical program evolved by MGGP. The inputs of the model are $a, b$, and $c$ and the functions used for the evolution process are $\times$, ,,$-+ \log$, and $\sqrt{ }$. The model is linear in the parameters with respect to the coefficients $\alpha_{0}, \alpha_{1}$, and $\alpha_{2}$ despite using nonlinear terms. As it is seen, the evolved model is a linear combination of nonlinear transformations of the predictor variables $[18,19]$. Two important MGGP parameters that need notable control are the maximum allowable number of genes and maximum tree depth. Restricting the tree depth mostly results in generating more compact models $[18,19]$.
In order to obtain the linear coefficients, an ordinary least squares analysis is performed on the training data. Besides, it is possible to embed multigene approach within a partial least squares method [34]. The initial population generated by MGGP contains GP trees with different randomly generated genes. In addition to traditional GP's recombination operators, MGGP uses a tree crossover operator, called twopoint high level crossover to acquire and delete the genes $[18,19]$. As an example, assume that two parent programs evolved by MGGP contain two (Gene 1 Gene 2) and three genes (Gene 3 Gene 4 Gene 5). The genes enclosed by the crossover points are denoted by \{\} as follows: (Gene 1 \{Gene 2$\}$ ) and (Gene 3 \{Gene 4 Gene 5$\}$ ). Thus, during the crossover operation the genes are exchanged to create two new programs: (Gene 1 Gene 4 Gene 5) and (Gene 3 Gene 2). In MGGP, standard GP subtree crossover is referred to as low level crossover. In this case, a gene is chosen at random from each parent individual. Then, the standard subtree crossover is applied and the created trees replace the parent trees in the unaltered individual in the next generation. Moreover, there are different types of mutation in MGGP such as subtree mutation, mutation of constants using an additive Gaussian perturbation, and set of a randomly selected constant to zero $[18,19]$. Further details about MGGP can be found in $[18,19]$.

\section{MGGP Modeling of Elastic Modulus of Concrete}

The modulus of elasticity is frequently formulated as a function of the compressive strength of concrete. Most of the national and international codes use this way to express the modulus of elasticity of concrete (e.g., American Concrete Code (ACI-318-95) [25], British Concrete Code (BS-8110) [28], and Canadian Concrete Code (CSA-A23.3) [29]). Thus, this study is aimed at developing explicit formulas for the tangent elastic modulus $\left(E_{c}\right)$ of normal strength concrete (NSC) and high strength concrete (HSC) in terms of compressive strength $\left(f_{c}\right)$ as follows:

$$
E_{c}=f\left(f_{c}\right)
$$

Hence, one parameter is used for the MGGP models as the input variable. The NSC and HSC databases are separately used to derive two different MGGP-based formulas for the $E_{c}$ of each of NSC and HSC. In order to propose a generic model for both of NSC and HSC, another MGGP model is developed based on the entire test results. Various parameters are involved in the MGGP predictive algorithm. These parameters selected are based on some previously suggested values [18-24], and after making several preliminary runs and observing the performance behavior. The parameter settings are shown in Table 1 . In this study, basic arithmetic operators and mathematical functions are utilized to get the optimum MGGP models. The number of programs in the population is set by the population size. The number of generation sets the number of levels the algorithm uses before the run terminates [18-20]. The proper number of population and generation often depends on the complexity 

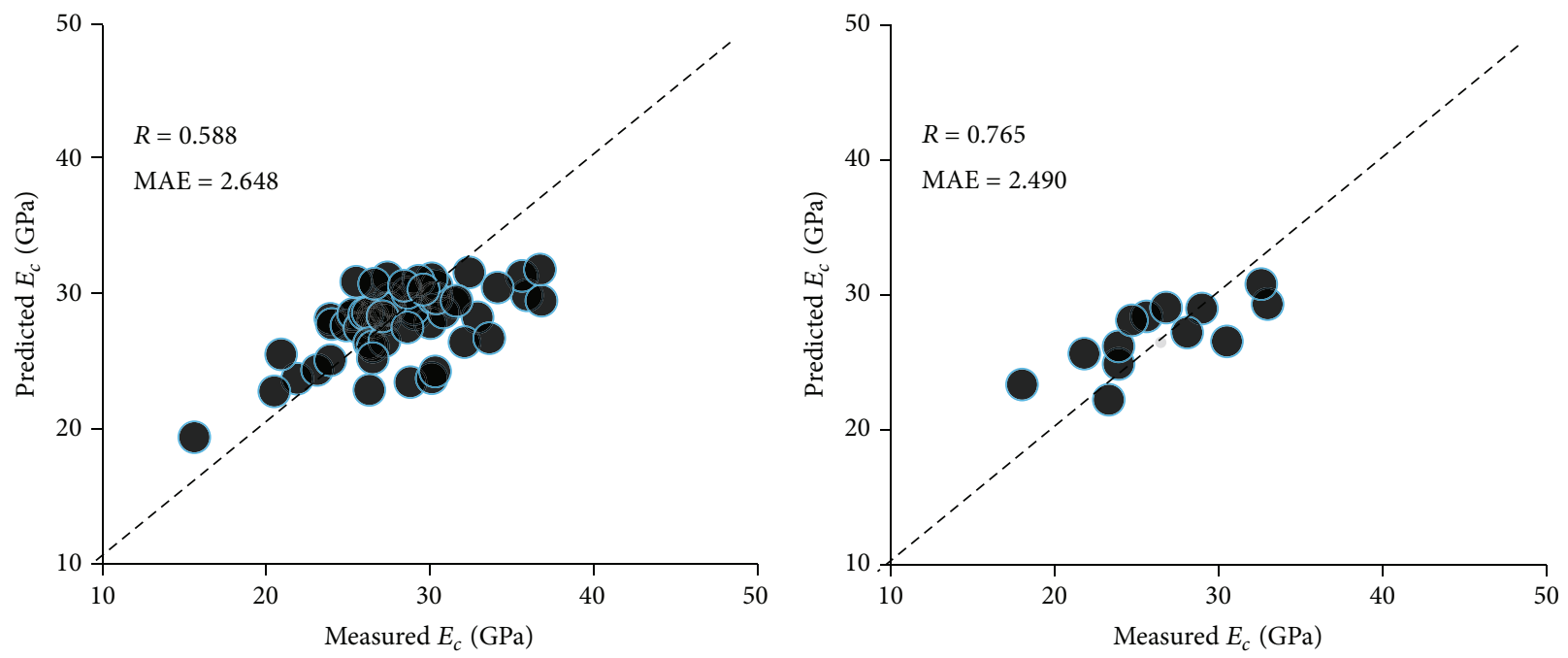

FIgURE 2: Predicted versus experimental $E_{c}$ of NSC using the MGGP I model.

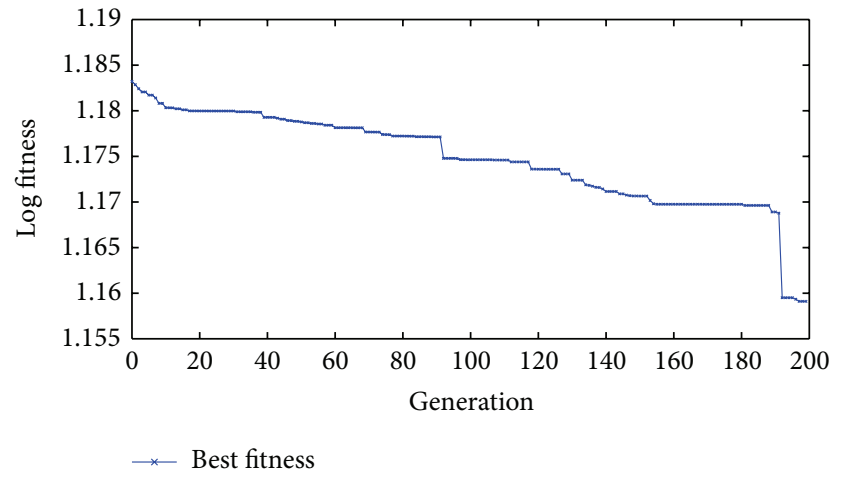

(a)

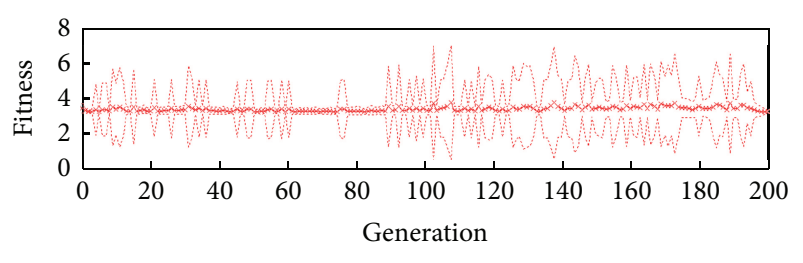

......... Mean fitness $( \pm 1$ std. dev.)

(b)

FIGURE 3: Variation of the best and mean fitness with the number of generations for MGGP I.

of problems and on the number of possible solutions. A fairly large number of population and generations are tested to find models with minimum error. The programs are run until the runs automatically terminated. The maximum allowable number of genes in an individual and the maximum tree depth directly influence the size of the search space and the number of solutions explored within the search space [1820]. The success of the MGGP algorithm usually increases

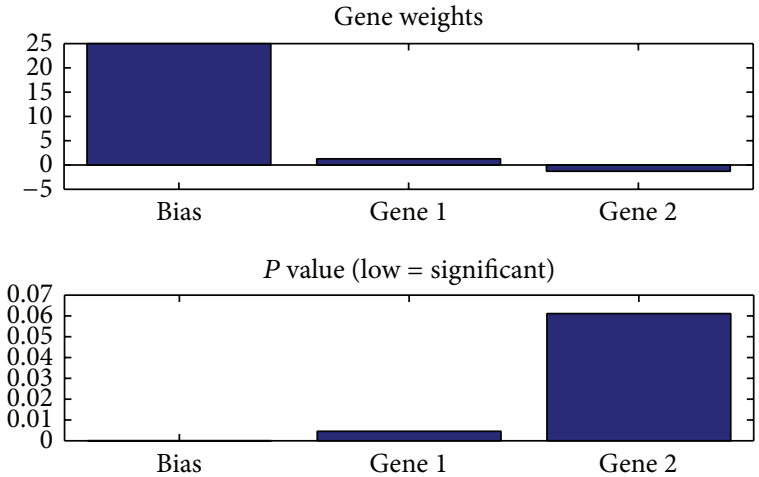

FIGURE 4: Statistical properties of the evolved MGGP I model (on training data).

with increasing these parameters. In this case, the complexity of the evolved function increases and the speed of the algorithm decreases. The allowable number of genes and tree depth are, respectively, set to optimal values as tradeoffs between the running time and the complexity of the evolved solutions [18-20]. There are $3 \times 3 \times 3 \times 2 \times 2 \times 2=$ 216 different combinations of the parameters. All of these parameter combinations are tested and 2 replications for each were carried out. Therefore, the overall number of optimal individual runs is equal to $216 \times 2=432$. GPTIPS toolbox [35], in conjunction with subroutines coded in MATLAB, is used to implement MGGP. Fitness function evaluates the evolved expressions to designate the best encoded expressions [19]. The default GPTIPS multigene symbolic regression function is used to minimize the error (root mean squared error).

The best MGGP models are chosen on the basis of providing the best fitness value on the training data as well as the simplicity of the models [3]. Correlation coefficient $(R)$ and mean absolute error (MAE) are used to evaluate the 

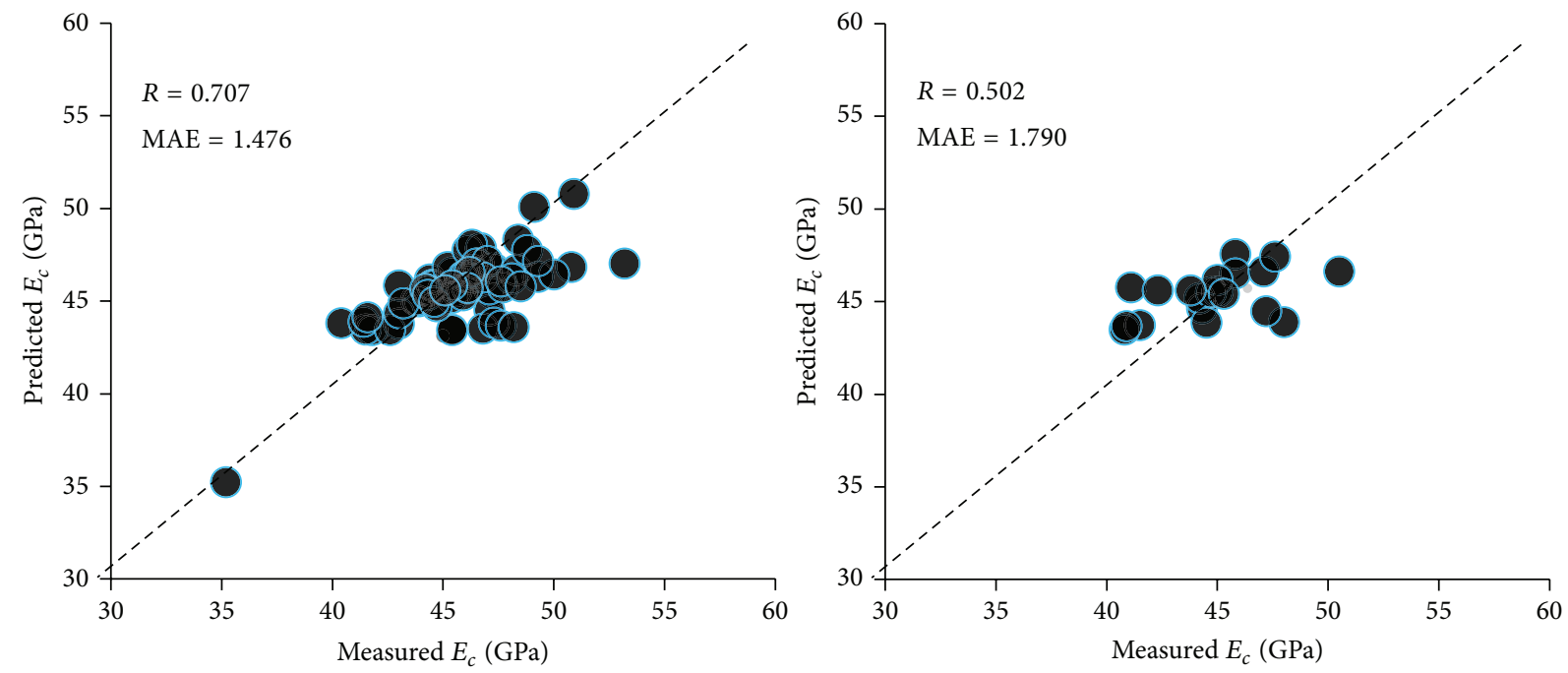

FIGURE 5: Predicted versus experimental $E_{c}$ of HSC using the MGGP II model.

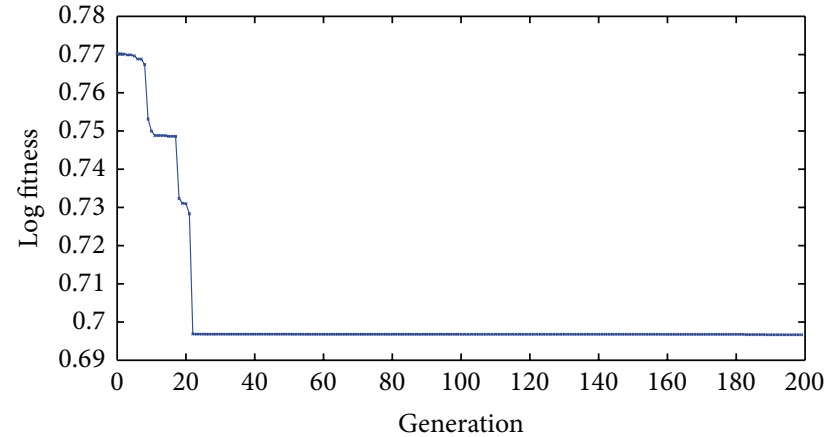

$\star$ Best fitness

(a)

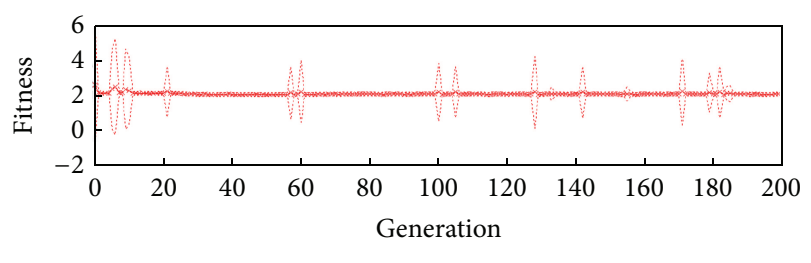

......... Mean fitness ( \pm 1 std. dev.)

(b)

FIgURE 6: Variation of the best and mean fitness with the number of generations for MGGP II.

performance of the models. $R$ and MAE are calculated using the following equations:

$$
\begin{gathered}
R=\frac{\sum_{i=1}^{n}\left(h_{i}-\overline{h_{i}}\right)\left(t_{i}-\overline{t_{i}}\right)}{\sqrt{\sum_{i=1}^{n}\left(h_{i}-\overline{h_{i}}\right)^{2} \sum_{i=1}^{n}\left(t_{i}-\overline{t_{i}}\right)^{2}}}, \\
\operatorname{MAE}=\frac{\sum_{i=1}^{n}\left|h_{i}-t_{i}\right|}{n} .
\end{gathered}
$$

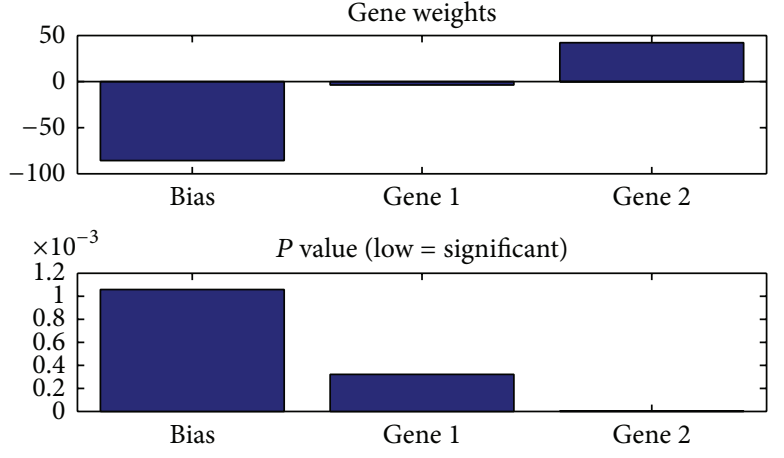

FIGURE 7: Statistical properties of the evolved MGGP II model (on training data).

3.1. Experimental Database. An experimental database of the previously published test results [36-39] is utilized to develop the models. This database has been previously employed by Demir [6], Demir [7], Gandomi et al. [3], Gandomi et al. [16], and Gandomi et al. [17] to develop the FL, ANN, LGP, GEP, and MEP models, respectively. The database contains 70 and 89 test results for the elastic modulus of NSC and HSC, respectively. The concrete specimens are tested at the age of 28 days. In the present study, a general model is further proposed for both of NSC and HSC using the entire data. For NSC, the ranges of the $E_{c}$ and $f_{c}$ are between 15.6-36.8 GPa and 14$47.7 \mathrm{MPa}$, respectively. The ranges of the $E_{c}$ and $f_{c}$ for HSC are between 35.2-53.2 GPa and 46.4-125.6 MPa, respectively. One of the data sets in the HSC database has a compressive strength lower than $50 \mathrm{MPa}$, which is mistakenly considered in the development of the other existing models. This data set is also included in the HSC database in order to conduct a fair comparison between the predictions provided by MGGP and other existing models. For the analysis, the data sets are divided into the training and testing subsets. Out of the 89 data sets for HSC, approximately $78 \%$ of the data (69 values) 

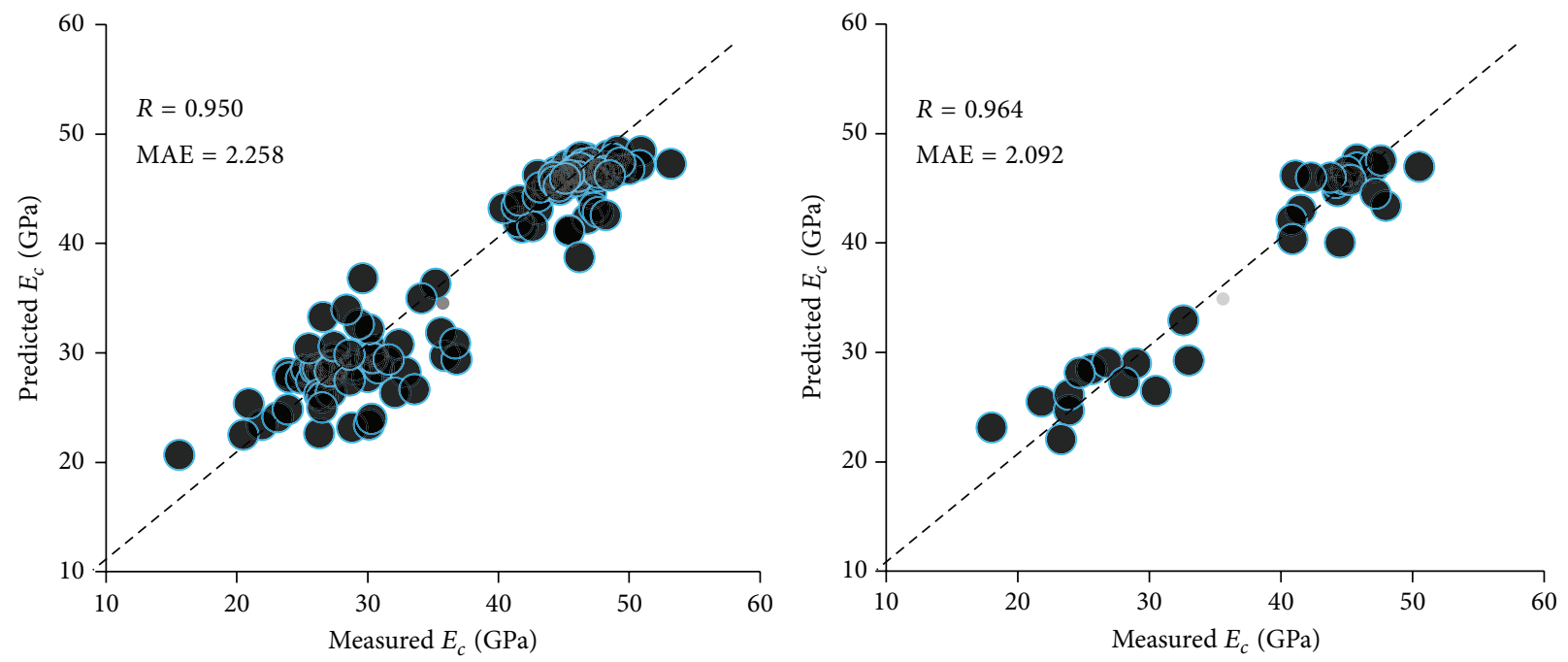

FIGURE 8: Predicted versus experimental $E_{c}$ of NSC and HSC using the MGGP III model.

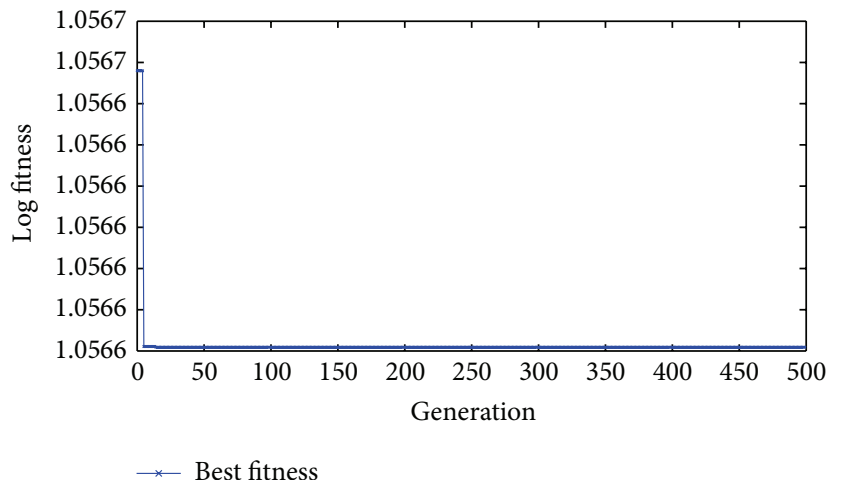

(a)

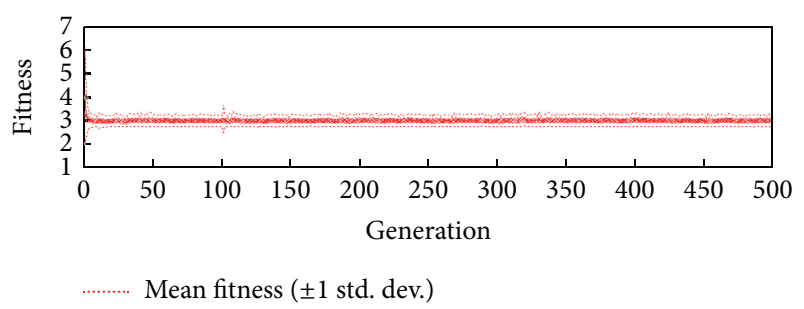

(b)

FIGURE 9: Variation of the best and mean fitness with the number of generations for MGGP III.

are taken for the training of the MGGP algorithm and the remaining 22\% (20 values) are used to test the generalization capability of the models. For NSC, approximately $80 \%$ of the data (57 values) are taken to train and the remaining 20\% (13 values) are used to test the models. Out of the total 159 data sets for NSC and HSC, almost $80 \%$ of the data (126 values) are taken for the training of the MGGP algorithm and the remaining 20\% (33 values) are used for the testing of the proposed NSC and HSC generic model $[3,16,17]$.
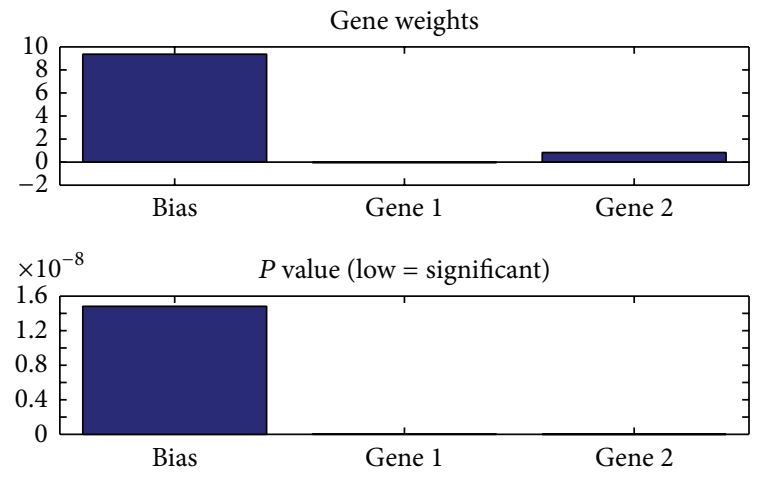

FIGURE 10: Statistical properties of the evolved MGGP III model (on training data).

TABLe 1: Parameter settings for the MGGP algorithm.

\begin{tabular}{lc}
\hline Parameter & Settings \\
\hline Population size & $200,500,1000$ \\
Number of generations & $200,500,1000$ \\
Maximum number of genes allowed & $1,3,6$ \\
in an individual & 4,6 \\
Maximum tree depth & 12 \\
Tournament size & $0.01 \%$ of population \\
Elitism & $0.1,0.85$ \\
Crossover events & 0.2 \\
High level crossover & 0.8 \\
Low level crossover & $0.1,0.85$ \\
Mutation events & 0.9 \\
Subtree mutation &,,$+- \times, /, \checkmark$, exp, ln, sin, cos \\
Function set &
\end{tabular}




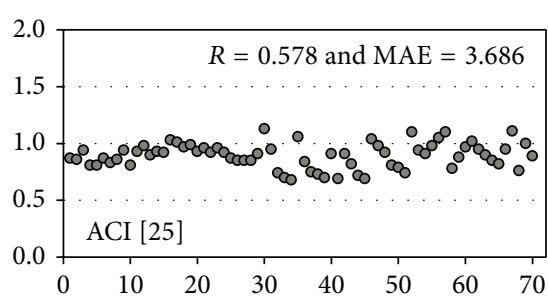

(a)

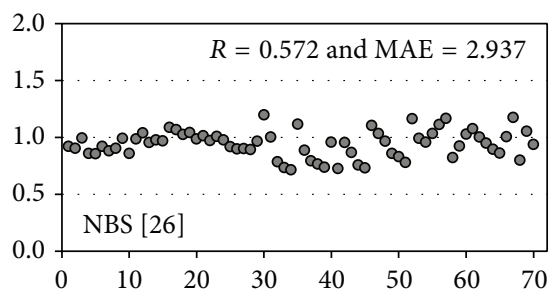

(d)

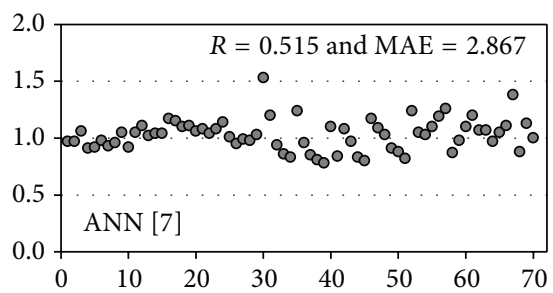

(g)

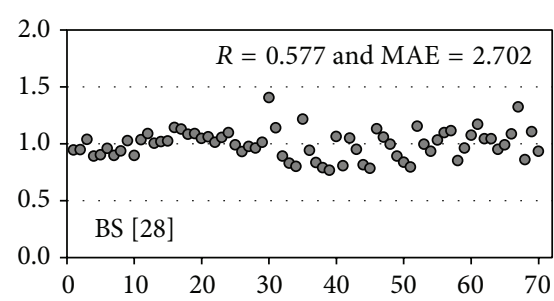

(b)

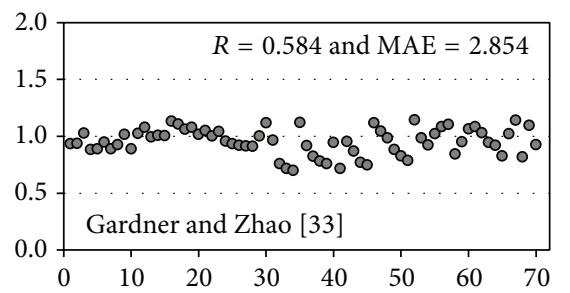

(e)

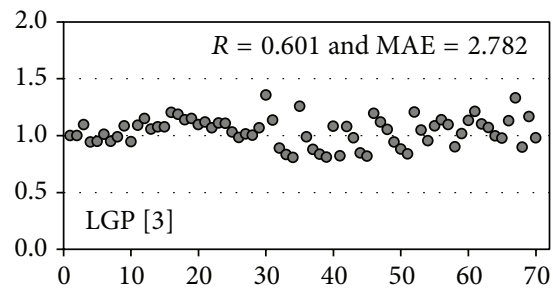

(h)

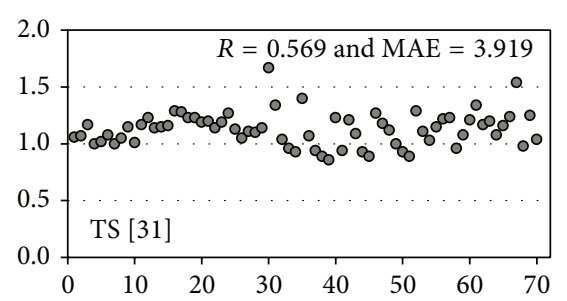

(c)

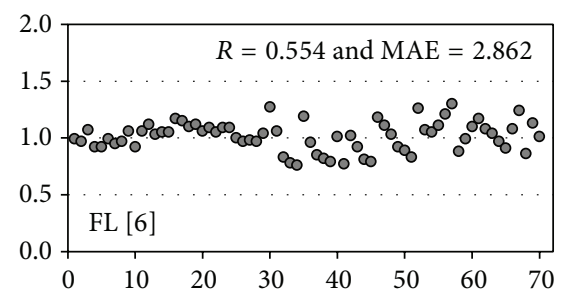

(f)

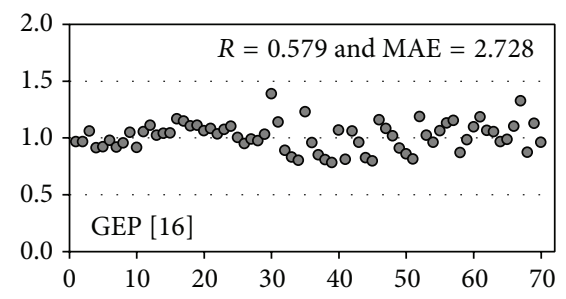

(i)

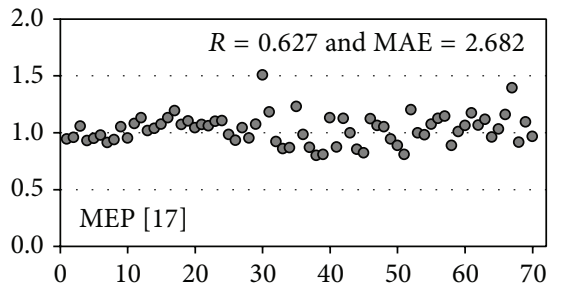

(j)

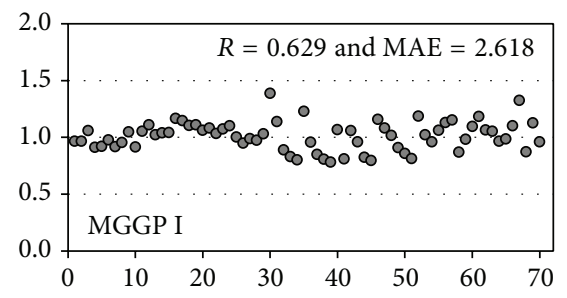

(k)

FIGURE 11: A comparison of the ratio between the predicted and experimental $E_{c}$ of NSC using different models. (Vertical axis: $E_{c, \text { Predicted }} / E_{c \text {, Experimental }}$; horizontal axis: test number.)

3.2. MGGP Prediction Model for the $E_{c}$ of NSC. The optimal formulation of the $E_{c}$ of NSC in terms of $f_{c}$ is as given below. The population size, number of generations, maximum number of genes, and maximum tree depth for the MGGP I model are 500,500, 6, and 4, respectively. The crossover and mutation rates are, respectively, equal to 0.85 and 0.85 :

$$
\begin{aligned}
E_{c, \text { MGGP I }}(\mathrm{GPa})= & 1.272 \sqrt{\left|\sqrt{f_{c}}-2 f_{c}+24.26\right|} \\
& -1.288 \sqrt{\left|33.21-f_{c}\right|}+24.98 .
\end{aligned}
$$

Figure 2 shows a comparison between the predicted and experimental $E_{c}$ values for NSC. As it is seen, the performance of the model on the testing data is better than training data. Figure 3 shows the variation of the best (log values) and mean fitness with the number of generations. It can be observed from this figure that the fitness value decreases with increasing the number of generations. The best fitness is found at the 197th generation. The statistical significance of each of the three genes of the derived model is visualized in Figure 4. According to Figure 4, the weight of the bias term is higher than the other genes. Figure 4 also depicts the degree of significance of each gene evaluated using $P$ values. As it is seen, the contribution of the genes to explain variations in $E_{c}$ is very high, as their relevant $P$ values are very low and are approximately equal to 0 . The statistical significance of the second gene (Gene 2) is lower than the bias term and the first gene.

3.3. MGGP Prediction Model for the $E_{c}$ of HSC. The optimal formulation of the $E_{c}$ of HSC in terms of $f_{c}$ is as follows. The population size, number of generations, maximum number of genes, and maximum tree depth for the MGGP II model are 500,1000, 3, and 4, respectively. The crossover 


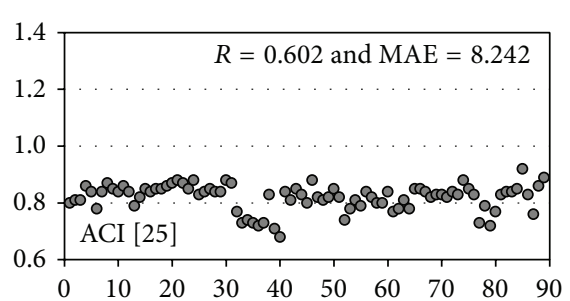

(a)

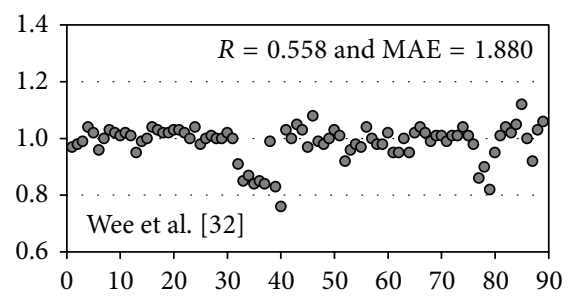

(d)

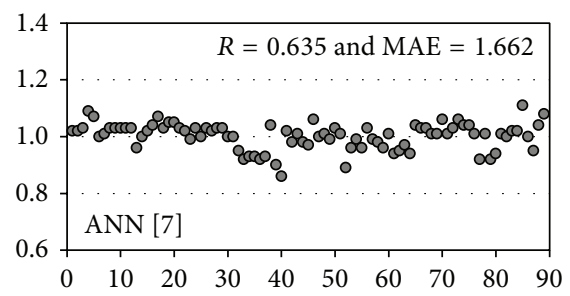

(g)

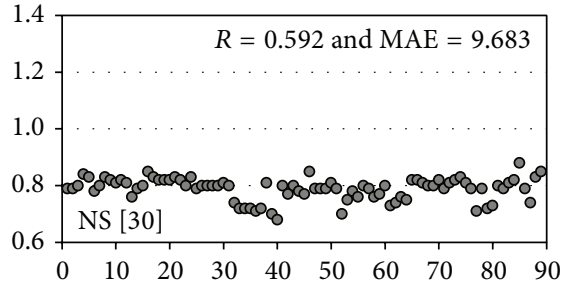

(b)

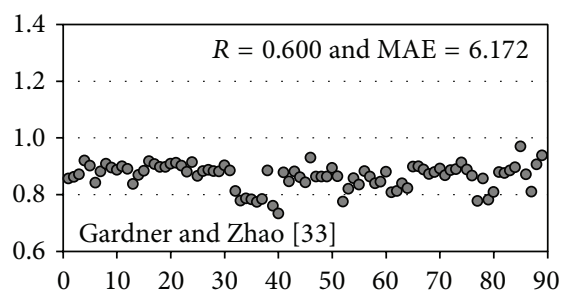

(e)

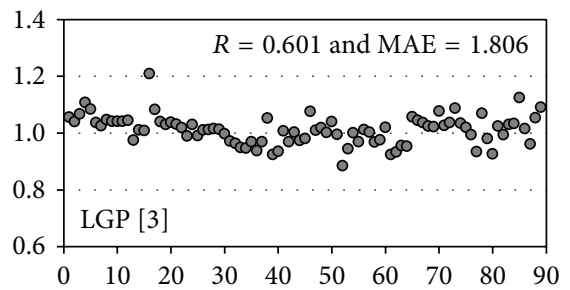

(h)



(c)

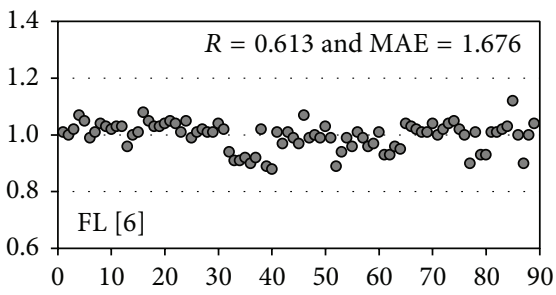

(f)

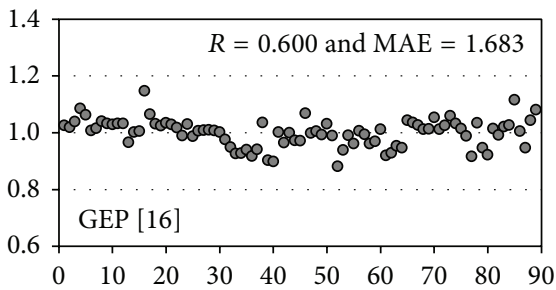

(i)

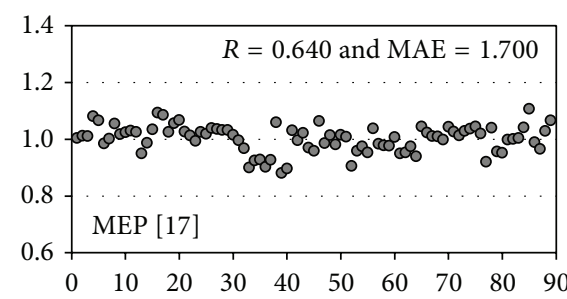

(j)

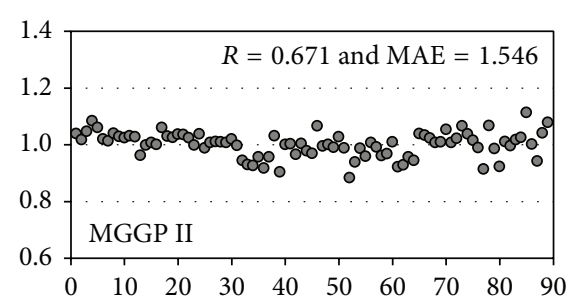

(k)

FIGURE 12: A comparison of the ratio between the predicted and experimental $E_{c}$ of HSC using different models. (Vertical axis: $E_{c, \text { Predicted }} / E_{c \text {, Experimental }}$; horizontal axis: test number.)

and mutation rates are, respectively, equal to 0.85 and 0.85 :

$$
\begin{aligned}
E_{c, \text { MGGP II }}(\mathrm{GPa})= & 42.2 \sqrt{\sqrt{\left|2 f_{c}-2.245\right|}} \\
& -3.655 \sqrt{\left|52.84-f_{c}\right|}-85.67 .
\end{aligned}
$$

Figure 5 presents a comparison between the predicted and experimental $E_{c}$ values for HSC. As it is seen, performance of the model on the training data is better than testing data. Although there is a probability that the model is slightly overfitted, it has been the best model obtained through the conducted runs. As can be seen in Figure 6, the fitness value decreases with increasing the number of generations. The best fitness is found at the 199th generation. According to Figure 7, the weight of the bias term is higher than the other genes. Figure 7 indicates that the contribution of the Genes 1 and 2 to explain variations in $E_{c}$ is higher than the bias term, as their relevant $P$ values are lower.

3.4. MGGP Prediction Model for the $E_{c}$ of NSC and HSC. The best prediction model for the $E_{c}$ of NSC and HSC in terms of $f_{c}$ is as given below. The population size, number of generations, maximum number of genes, and maximum tree depth for the MGGP III model are similar to those for the MGGP II model:

$$
\begin{aligned}
E_{c, \text { MGGP III }}(\mathrm{GPa})= & 0.8275 f_{c}+0.8783 \sqrt{f_{c}} \\
& -0.05251 f_{c} \sqrt{f_{c}}+8.562 .
\end{aligned}
$$

A comparison of the MGGP predicted values against experimental $E_{c}$ of NSC and HSC is shown in Figure 8. As can be seen in this figure, the performance of the model is very 


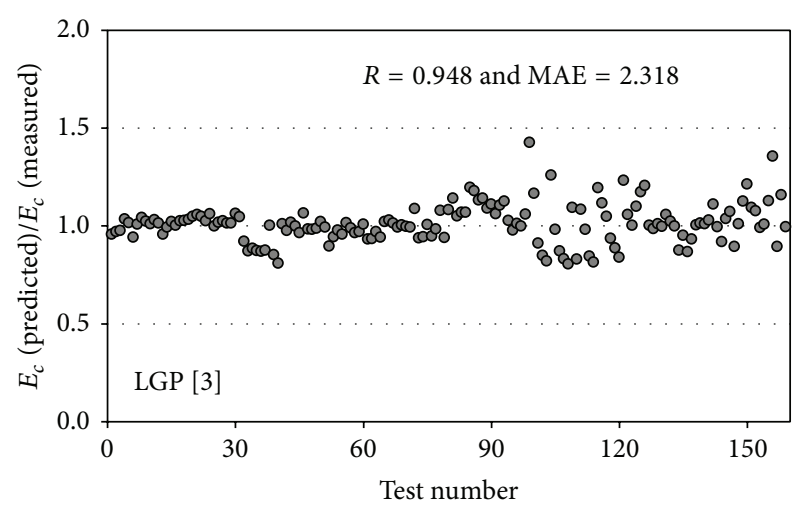

(a)

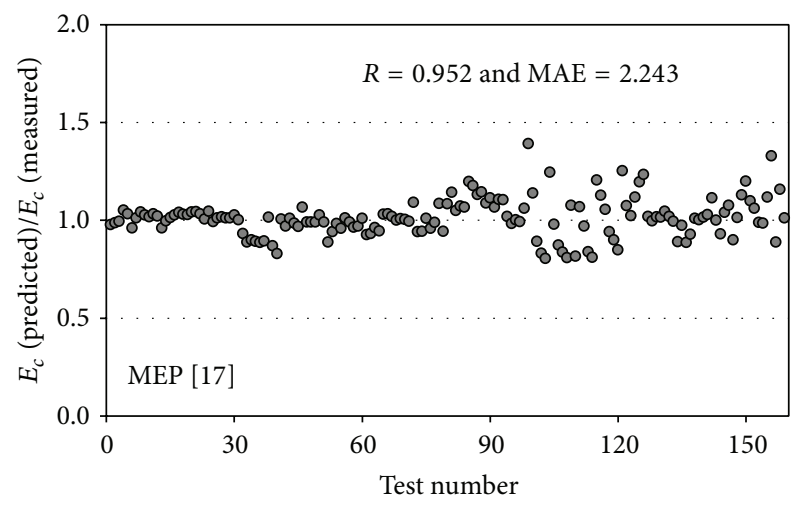

(c)

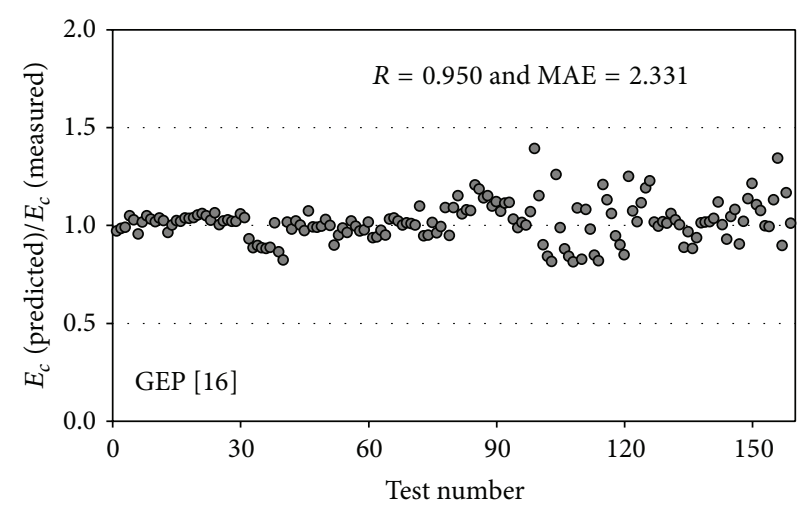

(b)

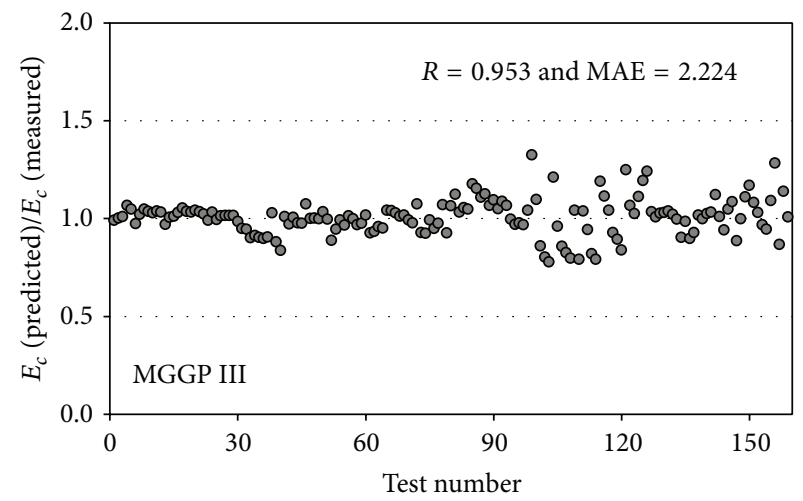

(d)

FIGURE 13: A comparison of the ratio between the predicted and experimental $E_{c}$ of NSC and HSC using different models.

good on both of the training and testing data. As can be seen in Figure 9, the best fitness is found at the 190th generation. According to Figure 10, the weight (coefficients) of the bias term is higher than the other genes. Figure 10 indicates that the contribution of the Genes 1 and 2 to explain the variations of $E_{c}$ is higher than the bias term, as their relevant $P$ values are lower.

\section{Performance Analysis}

Figures 11 and 12 illustrate the prediction performance of the MGGP models, American (ACI-318-95 [25]), Iranian (NBS [26]), European (CEB-FIB [27]), British (BS-8110 [28]), Canadian (CSA-A23.3 [29]), Norwegian (NS-3473 [30]), and Turkish (TS-500 [31]) codes, two compatibility aided models (i.e., Wee et al. [32] and Gardner and Zhao [33]), FL [6], ANN [7], LGP [3], GEP [16], and MEP [17] models for the $E_{c}$ of NSC and HSC, respectively. Moreover, the predictions made by available generalized models for the $E_{c}$ of both NSC and HSC are presented in Figure 13. These figures visualize the ratio of the predicted to experimental $E_{c}$ values. Apparently, a ratio closer to 1 indicates a more precise prediction. It can be seen from Figures 11 to 13 that the proposed MGGP models provide a significantly better performance than the available codes and empirical models. Moreover, MGGP makes better predictions than the robust soft computing tools (FL, ANN, LGP, GEP, and MEP). As shown in Figure 13, the proposed MGGP model for both of NSC and HSC yields very good results on the entire database. The superior performance of the generic model implies the reasonability of developing comprehensive models for the $E_{c}$ of both NSC and HSC rather than developing separate models for each of them.

\section{Parametric Analysis}

For further verification of the MGGP models, a parametric analysis is performed in this study. The parametric analysis investigates the response of the predicted $E_{c}$ by the MGGP models to a set of hypothetical input data. The robustness of the design equations is determined by examining how well the predicted $E_{c}$ values agree with the underlying physical behavior of NSC and HSC [40]. Figure 14 presents the tendency of the predictions to the $f_{c}$ variations. The results indicate that the $E_{c}$ of NSC and HSC continuously increases due to increasing $f_{c}$. The parametric analysis results are expected cases from a structural engineering viewpoint [41]. The results confirm that the proposed design equations are robust and can confidently be used.

\section{Conclusion}

In this paper, a promising extension of the classical GP, namely, MGGP, is employed for the analysis of the tangent 


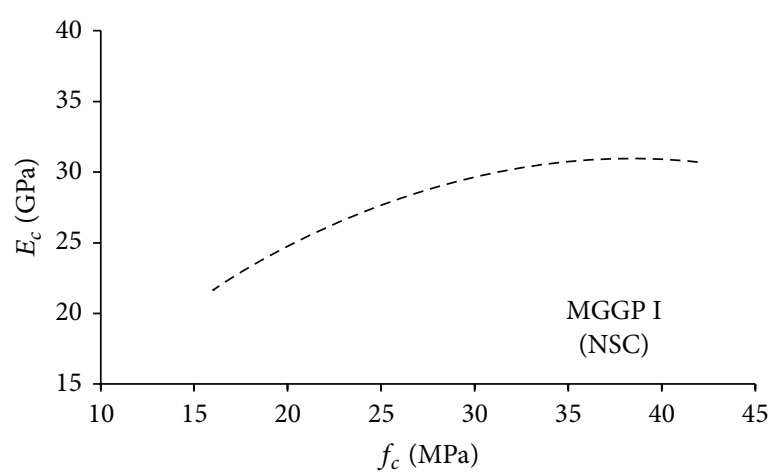

(a)

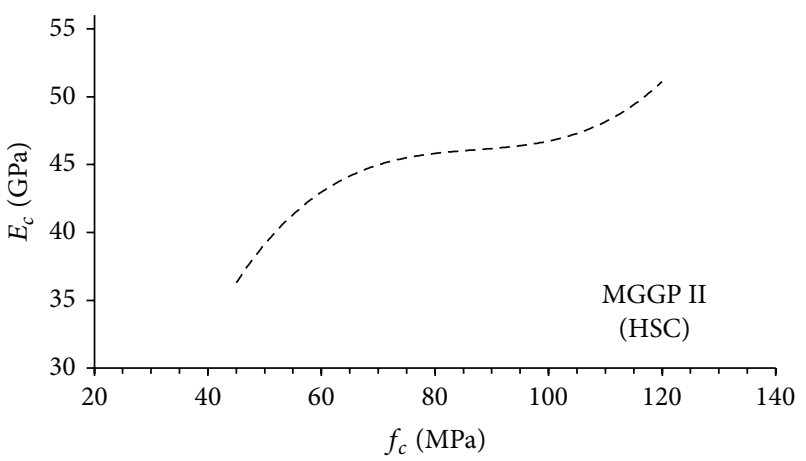

(b)

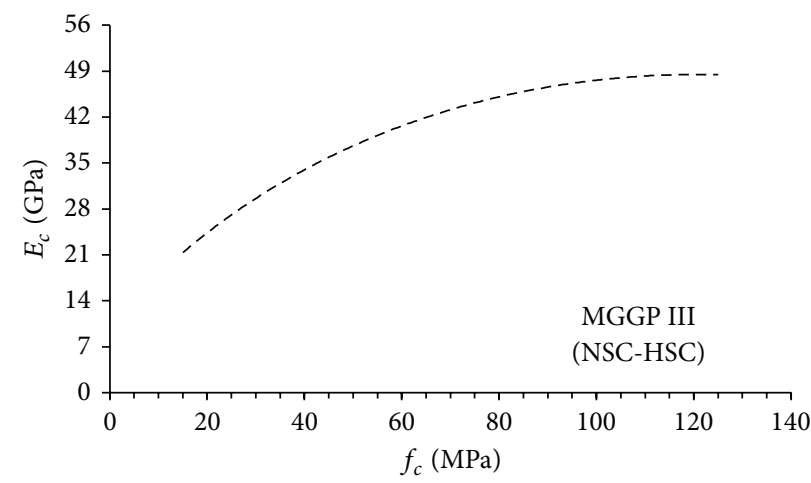

(c)

Figure 14: Parametric analysis of the $E_{c}$ of NSC and HSC.

$E_{c}$ of NSC and HSC. MGGP integrates the capabilities of the GP and linear regression methods to formulate the nonlinear behavior of $E_{c}$. Three design formulas are obtained for the prediction of $E_{c}$. The proposed models are developed upon several test results obtained from the literature. The MGGP models provide reliable estimations of the $E_{c}$ of NSC and HSC and outperform the existing empirical and other soft computing-based models. The generic MGGP model provides significantly accurate determinations of the $E_{c}$ of both NSC and HSC. In addition to the acceptable accuracy, the MGGP-based prediction equations are very simple. The robustness of the proposed MGGP models is confirmed with the results of the parametric study. With the use of the MGGP approach, $E_{c}$ can be estimated without carrying out sophisticated and time-consuming laboratory tests. The models can be easily retrained and improved to make more accurate predictions for a wider range by including the data for other test conditions [42].

\section{Conflict of Interests}

The authors declare that there is no conflict of interests regarding the publication of this paper.

\section{References}

[1] H. A. Mesbah, M. Lachemi, and P.-C. Aitcin, "Determination of elastic properties of high-performance concrete at early ages," ACI Materials Journal, vol. 99, no. 1, pp. 37-41, 2002.
[2] A. A. Khan, W. D. Cook, and D. Mitchell, "Early age compressive stress-strain properties of low-, medium, and high-strength concretes," ACI Materials Journal, vol. 92, no. 6, pp. 617-624, 1995.

[3] A. H. Gandomi, A. H. Alavi, M. G. Sahab, and P. Arjmandi, "Formulation of elastic modulus of concrete using linear genetic programming," Journal of Mechanical Science and Technology, vol. 24, no. 6, pp. 1273-1278, 2010.

[4] A. H. Alavi and A. H. Gandomi, "Energy-based numerical models for assessment of soil liquefaction," Geoscience Frontiers, vol. 3, no. 4, pp. 541-555, 2012.

[5] A. H. Alavi and A. H. Gandomi, "A robust data mining approach for formulation of geotechnical engineering systems," Engineering Computations, vol. 28, no. 3, pp. 242-274, 2011.

[6] F. Demir, "A new way of prediction elastic modulus of normal and high strength concrete-fuzzy logic," Cement and Concrete Research, vol. 35, no. 8, pp. 1531-1538, 2005.

[7] F. Demir, "Prediction of elastic modulus of normal and high strength concrete by artificial neural networks," Construction and Building Materials, vol. 22, no. 7, pp. 1428-1435, 2008.

[8] K. Yan and C. Shi, "Prediction of elastic modulus of normal and high strength concrete by support vector machine," Construction and Building Materials, vol. 24, no. 8, pp. 1479-1485, 2010.

[9] A. C. Aydin, A. Tortum, and M. Yavuz, "Prediction of concrete elastic modulus using adaptive neuro-fuzzy inference system," Civil Engineering and Environmental Systems, vol. 23, no. 4, pp. 295-309, 2006.

[10] B. Ahmadi-Nedushan, "Prediction of elastic modulus of normal and high strength concrete using ANFIS and optimal nonlinear 
regression models," Construction and Building Materials, vol. 36, pp. 665-673, 2012.

[11] J. Koza, Genetic Programming: On the Programming of Computers by Means of Natural Selection, MIT Press, Cambridge, Mass, USA, 1992.

[12] A. H. Alavi, A. H. Gandomi, M. Modaresnezhad, and M. Mousavi, "New ground-motion prediction equations using multi expression programing," Journal of Earthquake Engineering, vol. 15, no. 4, pp. 511-536, 2011.

[13] A. H. Alavi, A. H. Gandomi, M. G. Sahab, and M. Gandomi, "Multi expression programming: a new approach to formulation of soil classification," Engineering with Computers, vol. 26, no. 2, pp. 111-118, 2010.

[14] A. H. Gandomi and A. H. Alavi, "Expression programming techniques for formulation of structural engineering systems," in Metaheuristic Applications in Structures and Infrastructures, A. H. Gandomi, X.-S. Yang, S. Talatahari, and A. H. Alavi, Eds., chapter 18, Elsevier, Waltham, Mass, USA, 2013.

[15] A. H. Gandomi, A. H. Alavi, and M. G. Sahab, "New formulation for compressive strength of CFRP confined concrete cylinders using linear genetic programming," Materials and Structures, vol. 43, no. 7, pp. 963-983, 2010.

[16] A. H. Gandomi, A. H. Alavi, T. O. Ting, and X. S. Yang, "Intelligent modeling and prediction of elastic modulus of concrete strength via gene expression programming," in Advances in Swarm Intelligence, vol. 7928 of Lecture Notes in Computer Science, pp. 564-571, Springer, Berlin, Germany, 2013.

[17] A. H. Gandomi, A. Faramarzifar, A. H. Alavi, P. Ghanad-Rezaee, S. Talatahari, and A. Asghari, "New design equationsfor elastic modulus of concrete using multi expression programming," Journal of Civil Engineering and Management. In press.

[18] D. P. Searson, D. E. Leahy, and M. J. Willis, "GPTIPS:An open source genetic programming toolbox for multigene symbolic regression," in Proceedings of the International MultiConference of Engineers and Computer Scientists (IMECS '10), pp. 77-80, Hong Kong, March 2010.

[19] A. H. Gandomi and A. H. Alavi, "A new multi-gene genetic programming approach to nonlinear system modeling-part I: materials and structural engineering problems," Neural Computing and Applications, vol. 21, no. 1, pp. 171-187, 2012.

[20] A. H. Gandomi and A. H. Alavi, "A new multi-gene genetic programming approach to non-linear system modeling-part II: geotechnical and earthquake engineering problems," Neural Computing and Applications, vol. 21, no. 1, pp. 189-201, 2012.

[21] K. Gopalakrishnan, S. Kim, H. Ceylan, and S. K. Khaitan, "Natural selection of asphalt stiffness predictive models with genetic programming," in Proceedings of the Artificial Neural Networks in Engineering (ANNIE '10), C. H. Dagli, A. L. Buczak, D. L. Enke, M. Embrechts, and O. Ersoy, Eds., St. Louis, Mo, USA, November 2010.

[22] C. K. Desai and A. Shaikh, "Prediction of depth of cut for single-pass laser micro-milling process using semi-analytical, ANN and GP approaches," International Journal of Advanced Manufacturing Technology, vol. 60, pp. 865-882, 2012.

[23] M. Rezaei, M. Eftekhari, S. Mahin, and M. Ranjbar, "A $\mathrm{CO}_{2}$ oil minimum miscibility pressure model based on multi-gene genetic programming," Energy, Exploration \& Exploitation, vol. 31, pp. 607-622, 2013.

[24] P. K. Muduli and S. K. Das, "CPT-based seismic liquefaction potential evaluation using multi-gene genetic programming approach," Indian Geotechnical Journal, vol. 44, no. 1, pp. 86-93, 2014.
[25] ACI-318-95, "Building code requirements for structural concrete," ACI Manual of Concrete Practice Part 3: Use of Concrete in Buildings -Design, Specifications, and Related Topics, ACI, Detroit, Mich, USA, 1996.

[26] NBS, "Analysis and Design of Reinforced Concrete Buildings," National Building Standard, Part 9, 2006.

[27] CEB, CEB-FIB Model Code, Bulletin d'Information no. 213/214, CEB, Lausanne, Switzerland, 1993.

[28] BS-8110, Part 2, British Standard Institution, 1985.

[29] CSA-A23. 3-94, Design of Concrete Structures, Canadian Standard Association, Rexdale, Canada, 1995.

[30] NS-3473, Concrete Structures Design Rules, Norwegian Council for Building Standardization, Stockholm, Sweden, 1992.

[31] TS-500, Requirements for Design and Construction of Reinforced Concrete Structures, Turkish Standardization Institute, Ankara, Turkey, 2000.

[32] T. H. Wee, M. S. Chin, and M. A. Mansur, "Stress-strain relationship of high-strength concrete in compression," Journal of Materials in Civil Engineering, vol. 8, no. 2, pp. 70-76, 1996.

[33] N. J. Gardner and J. W. Zhao, "Creep and shrinkage revisited," ACI Materials Journal, vol. 90, no. 3, pp. 236-246, 1993.

[34] D. Searson, M. Willis, and G. Montague, "Co-evolution of nonlinear PLS model components," Journal of Chemometrics, vol. 21, no. 12, pp. 592-603, 2007.

[35] D. P. Searson, "GPTIPS: Genetic Programming \& Symbolic Regression for MATLAB," 2009.

[36] M. Gesoǧlu, E. Güneyisi, and T. Özturan, "Effects of end conditions on compressive strength and static elastic modulus of very high strength concrete," Cement and Concrete Research, vol. 32, no. 10, pp. 1545-1550, 2002.

[37] T. Ozturan, An investigation of concrete abrasion as two phase material [Ph.D. thesis], Faculty of Civil Engineering, Istanbul Technical University, Istanbul, Turkey, 1984.

[38] M. Turan and M. Iren, "Strain stress relationship of concrete," Journal of Engineering and Architecture, vol. 12, no. 1, pp. 76-81, 1997.

[39] M. J. Shannag, "High strength concrete containing natural pozzolan and silica fume," Cement and Concrete Composites, vol. 22, no. 6, pp. 399-406, 2000.

[40] Y. L. Kuo, M. B. Jaksa, A. V. Lyamin, and W. S. Kaggwa, "ANNbased model for predicting the bearing capacity of strip footing on multi-layered cohesive soil," Computers and Geotechnics, vol. 36, no. 3, pp. 503-516, 2009.

[41] F. de Larrard and A. Belloc, "The influence of aggregate on the compressive strength of normal and high-strength concrete," ACI Materials Journal, vol. 94, no. 5, pp. 417-426, 1997.

[42] S. M. Mousavi, P. Aminian, A. H. Gandomi, A. H. Alavi, and H. Bolandi, "A new predictive model for compressive strength of HPC using gene expression programming," Advances in Engineering Software, vol. 45, no. 1, pp. 105-114, 2012. 


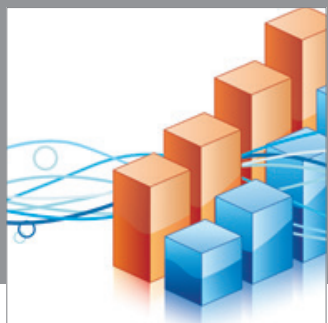

Advances in

Operations Research

mansans

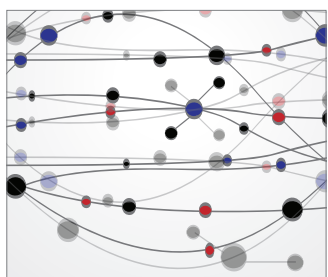

The Scientific World Journal
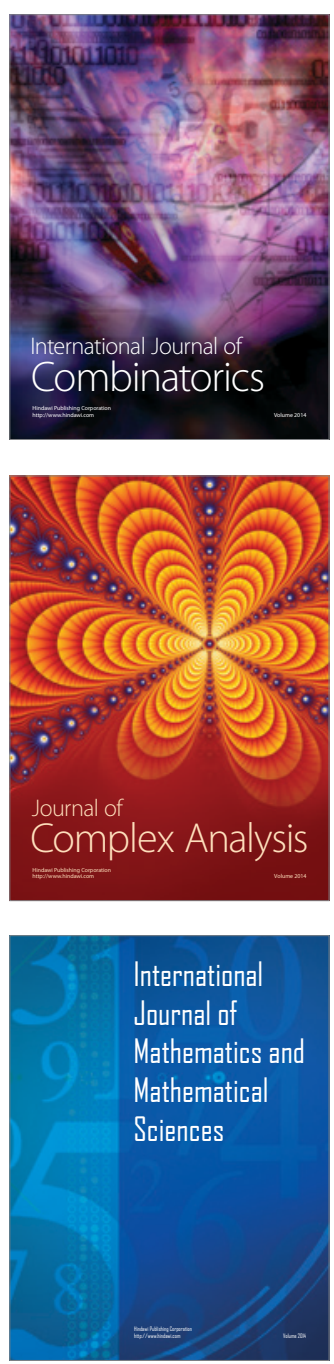
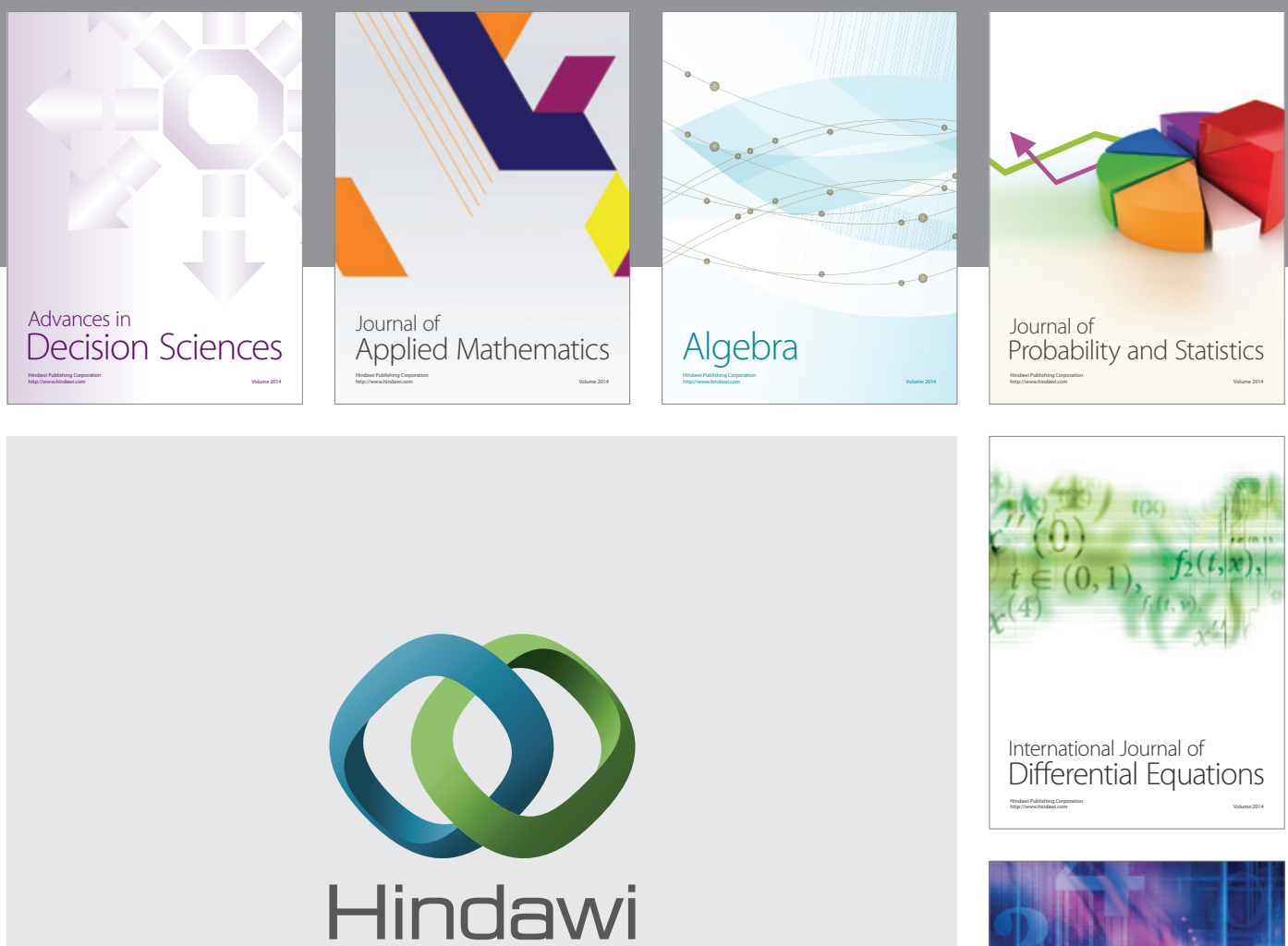

Submit your manuscripts at http://www.hindawi.com
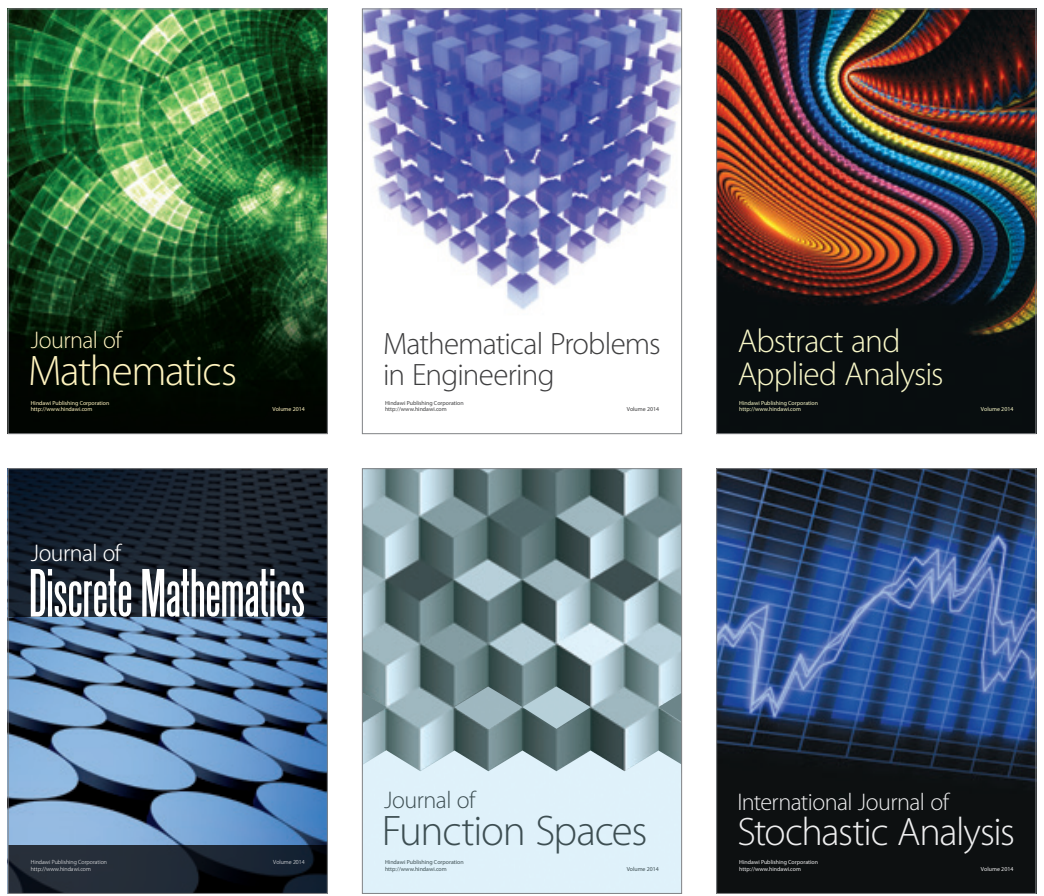

Journal of

Function Spaces

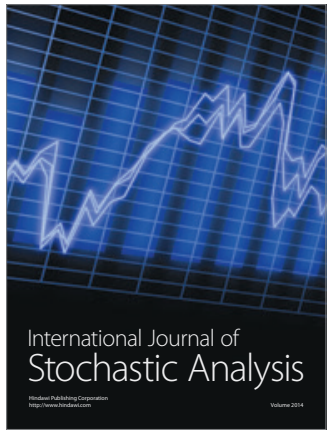

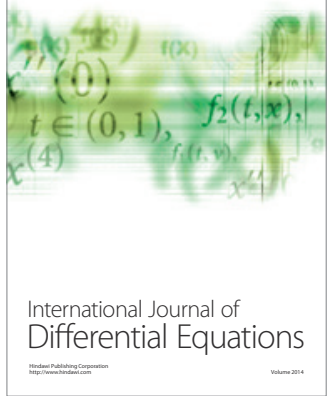
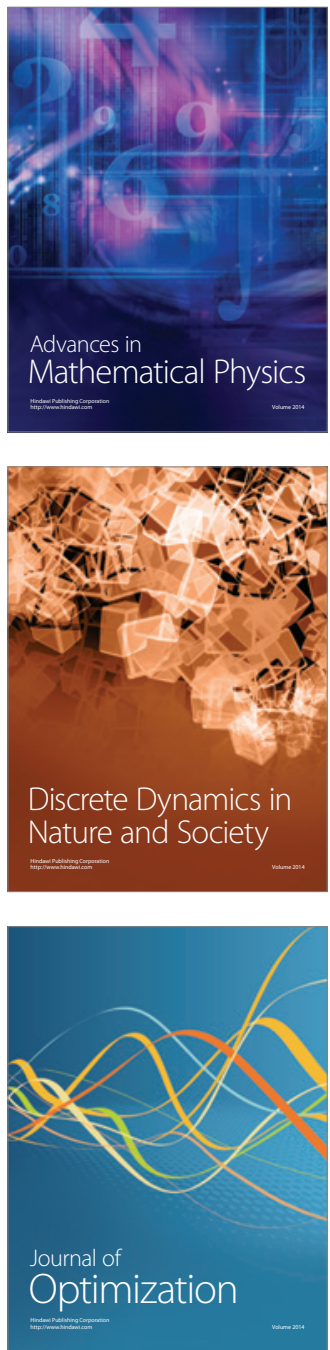